\title{
The Intuitive Basis for Contextualism
}

(for The Routledge Handbook of Epistemic Contextualism, edited by Jonathan Jenkins Ichikawa)

\author{
Geoff Pynn
}

FINAL VERSION: September 12, 2016

Francois follows climate science closely, and on this basis she believes, correctly, that the earth's mean temperature will continue to rise over the next century. Does she know this? Many would say that she does. Her belief is based on her accurate understanding of the scientific consensus, and we typically treat scientific expertise as a source of knowledge. On the other hand, you might deny that she knows that the temperature will continue to rise, even if you agree that this is likely. After all, climate scientists themselves readily acknowledge that their predictions are not entirely certain. So while Francois may be justified in her belief, she doesn't really know. Which answer is right, then? Does Francois know? Or not? Contextualists think that which answer is correct depends, in part, on the context in which the question is asked. Whether Francois can truly claim to know depends on her context's "epistemic standard," which determines how strong her epistemic position must be in order for her to count as knowing in that context --- how much evidence she needs, which alternatives she needs to be able to rule out, how reliable her belief-forming mechanisms need to be, and so on. So according to the contextualist, Francois can truly claim to know that the temperature will continue to rise in a context where the epistemic standard is relatively relaxed, but not in a context where the epistemic standard is particularly demanding.

This chapter outlines the intuitive argument for contextualism. To a substantial degree, my presentation follows that of Keith DeRose, who has done more than any other contextualist to develop the argument (see especially DeRose 1992, 2005, 2009 (ch.2)). The overall shape of the argument is an inference to the best explanation: contextualism, it is claimed, is part of the best explanation for the 
variability in epistemic standards exhibited by our ordinary knowledge talk. The argument is "intuitive" in that it relies upon intuitive judgments about ordinary knowledge claims. The contents of these judgments furnish the data that contextualism explains. By calling the judgments "intuitive," I mean two things: first, they are more-or-less non-inferential and cognitively effortless; second, they are generated by intellectual reflection or imagination, rather than perception (Nagel2007, Nado and Johnson 2014). When I say that something "intuitively seems" to be the case, I mean that we (I and, hopefully, the reader) are inclined to make an intuitive judgment that it is the case. When I say that an intuitive judgment is "accepted," or that we "defer to" an intuition or intuitive judgment, I mean that we accept that the judgment's content is true.

\section{Low-High Pairs and The Intuitions They Elicit}

The case for contextualism starts with the observation that we apply different epistemic standards in different contexts when making and evaluating knowledge claims. This observation will not be news to anyone who has been exposed to radical skeptical arguments. When well-constructed and successfully deployed, such arguments lead us temporarily to apply much higher epistemic standards than we ordinarily do, and hence to conclude that we don't know much. Still, as Hume pointed out, even skeptics regard themselves as knowers once the skeptical spell has been lifted: "[T]he first and most trivial event in life will put to flight all their doubts and scruples, and leave them the same, in every point of action and speculation, with the philosophers of every other sect, or with those who never concerned themselves in any philosophical researches" (Hume 1999, 207). One can see the debate over radical skepticism as a debate about which epistemic standard is correct: the very high standard introduced by the skeptic, or the more manageable one in place once our doubts and scruples have been put to flight. Contextualists claim to be able to resolve, or dissolve, this debate: different standards apply in different contexts, so neither one is "correct" tout court (see Chapter 10). But the contextualist resolution might appear ad hoc. 
Couldn't nearly any philosophical dispute be "resolved" by stipulating that some term at the heart of the dispute has a meaning that varies with context? To avoid this charge, we need independent reason to accept that contextualism is true.

Contextualists argue that shifts in epistemic standards like those triggered by a skeptic's intervention are ubiquitous in ordinary conversations. They present us with pairs of imaginary vignettes to illustrate this variability. In the "Low" vignette, a speaker in some mundane situation claims that a subject knows some proposition. In the "High" vignette, a speaker in a different situation claims that the same subject doesn't know that same proposition. When the vignettes are well constructed, both the positive knowledge claim in the Low case and the negative knowledge claim in the High case seem true. I'll call such cases Low-High pairs. Here is a well-known Low-High pair from Keith DeRose:

Low Bank Case. My wife and I are driving home on a Friday afternoon. We plan to stop at the bank on the way home to deposit our paychecks. But as we drive past the bank, we notice that the lines inside are very long, as they often are on Friday afternoons. Although we generally like to deposit our paychecks as soon as possible, it is not especially important in this case that they be deposited right away, so I suggest that we drive straight home and deposit our paychecks on Saturday morning. My wife says, "Maybe the bank won't be open tomorrow. Lots of banks are closed on Saturdays." I reply, 'No, I know it'll be open. I was just there two weeks ago on Saturday. It's open until noon.”

High Bank Case. My wife and I drive past the bank on a Friday afternoon, as in [Low Bank Case], and notice the long lines. I again suggest that we deposit our paychecks on Saturday morning, explaining that I was at the bank on Saturday morning only two weeks ago and discovered that it was open until noon. But in this case, we have just written a very large and very important check. If our paychecks are not deposited into our checking account before Monday morning, the important check we wrote will bounce, leaving us in a very bad situation. And, of 
course, the bank is not open on Sunday. My wife reminds me of these facts. She then says, "Banks do change their hours. Do you know the bank will be open tomorrow?" Remaining as confident as I was before that the bank will be open then, still, I reply, "Well, no, I don't know. I'd better go in and check" (DeRose 1992, 913; DeRose 2009, 1-2).

In Low, it doesn't matter very much whether Keith is right about the bank's hours, and no hypotheses about how he could be wrong has been raised. In High, it matters a lot whether he is right, and a particular hypothesis about how he might be wrong ("Banks do change their hours") has been raised. What leads Keith to deny that he knows in High is not an argument for philosophical skepticism, but his awareness of the ordinary ways he could go wrong, and the exigencies of everyday life.

The intuitive argument for contextualism doesn't rest upon any particular Low-High pair such as the bank cases or Stuart Cohen's equally well-known airport cases (Cohen 1999). Such cases are rather meant to illustrate a pervasive variability in our ordinary knowledge talk, which contextualism (it is argued) best explains. Nonetheless, it simplifies matters to present the argument as if a particular pair of cases were essential to it. There should be no danger in this, provided we bear in mind that the contrast between the bank cases is meant to be representative of a ubiquitous phenomenon. So construed, the key claim in the case for contextualism is:

Truth. Keith's claim to know in Low and his claim not to know in High are both true.

Truth, in turn, is underwritten by two intuitive judgments.

First, considered from the perspective of the context in which it was made, each claim seems true. As DeRose puts it, contextualists "appeal to how we, competent speakers, intuitively evaluate the truthvalues of particular claims that are made (or are imagined to have been made) in particular situations" (DeRose 2009, 49). Imagine yourself in each conversation, and ask whether the claim Keith makes in that conversation is true (assuming, of course, that the bank will in fact be open); the contextualist thinks that 
you'll find yourself answering, "Yes." Second, each claim is intuitively appropriate. A claim can be (and seem) true without being (or seeming) appropriate. Asked by a friend who's run out of gas if there is a filling station nearby, I claim that there is one around the corner, without revealing that I know that it has been closed for months. My claim is true but misleading, and hence improper. However, the propriety of a claim is evidence for its truth, since it is generally improper to make a false claim. Not always: hyperbolic and other figurative claims can be proper though false ("It took me a million years to get through Husserl's Logical Investigations!"). Nonetheless, such cases are exceptional, and neither of Keith's claims seems at all figurative (pace Hazlett 2007 and Schaffer 2004).

It's important to see that neither of these intuitions constitutes a judgment about what Keith knows or doesn't know. For a contextualist, the question of what a subject knows is different from the question of what knowledge claims are true of her. To say that Keith knows would be to claim, in effect, that he meets the epistemic standards in place in our present context. The case for contextualism does not rest on an intuitive judgment that Keith meets or doesn't meet the epistemic standards in place in the context of a philosophical discussion about knowledge or knowledge claims. Rather, it rests on the judgment that Keith's knowledge claims, as made in their imagined contexts, are true. Contextualists typically refrain from issuing or endorsing any first-order judgment about whether the characters in their vignettes know or don't know. DeRose, for example, says that his intuitions about the "object-level question" of whether the characters in his story know "would be far more wavering and uncertain than are my intuitions that the claims made in the cases are true" (DeRose 2009, 49). Similarly, when arguing for contextualism using his airport cases, Stewart Cohen is concerned with whether the speakers use the word 'know' correctly, and whether they speak truly, and not with whether the subject of their knowledge attributions knows (Cohen 1999, 58ff.).

The intuitions are also not judgments about the sentences that Keith has uttered. Standard contextualism does treat both sentences as true with respect to their context of utterance. And contextualists are not always careful about distinguishing the truth of a sentence from the truth of a claim made by uttering the sentence (though see Stainton 2010 and Pynn 2015). This is partly because 
contextualists typically presuppose that what Keith claims in each case just is the content encoded by the sentence he utters with respect to its context. If a claim's content and truth-value are identified with the content and truth-value of the sentence uttered in making the claim, then Truth implies that the sentences Keith utters in both cases are true. But the intuitive judgments at play in the argument concern the truth and propriety of Keith's claims, and not the sentences he utters in making them. ${ }^{1}$

By and large, contextualists and their opponents have agreed that Keith's claims are intuitively proper and true; controversy has concerned how to accommodate these intuitions, not what they are. Recently, however, work in "experimental philosophy" has been used to raise doubts about the intuitions themselves. Citing surveys designed to elicit judgments about Low-High pairs, Jonathan Schaffer and Joshua Knobe assert that "people simply do not have the intuitions they were purported to have," suggesting that "the whole contextualism debate was founded on a myth" (Schaffer and Knobe 2012, 675). Chapter 3 discusses this issue in more detail. Two brief responses are worth making.

First, some of the data cited by Schaffer and Knobe is neutral with respect to the intuitive judgments just canvassed (see DeRose 2011 for discussion). Two of the surveys ask subjects about whether various characters in Low-High pairs know, rather than whether speakers who claim to know speak truly. A third study (Buckwalter 2010) asked subjects whether the speaker in a Low case who claims to know speaks truly, but then, in a departure from contextualist Low-High pairs, asked whether a speaker in a High-like case who also claims to know speaks truly. Only the fourth study (Feltz and Zarpentine 2010) involved a survey in which the bank cases were presented more-or-less as originally constructed. In Feltz and Zarpentine's study, the average level of agreement that the claims made in High and Low were true was around 4 on a 7-point Likert scale. While this result does not confirm the contextualist's claims about the intuitions, neither does it disconfirm them; it is neutral.

\footnotetext{
${ }^{1}$ To see the difference, it may be helpful to focus on the actual sentence that features in the High bank case: "Well, no, I don't know." Speaking for myself, I have no intuition whatsoever about whether that sentence is true. I am inclined to say that it is neither true nor false, because it is semantically incomplete, since it has no element corresponding to what Keith is claiming not to know.
} 
Second, more recent work than that cited by Schaffer and Knobe suggests that the intuition of truth in Low and High is, in fact, widely shared. Hansen and Chemla 2013 “confirmed DeRose's prediction that speakers would find both 'I know that p' in the Low context and 'I don't know that P' in the High context true" (Hansen and Chemla 2013, 203). And Buckwalter 2014 designed a new survey where speakers were asked about the truth of knowledge attributions and denials made in various Low and High cases, and found that subjects "generally judged everything true across the board" (Buckwalter 2014, 156). ${ }^{2}$ In light of this subsequent work, we have reason to doubt Schaffer and Knobe's assertion that contextualism is founded on an intuitive myth. Nonetheless, the empirical adequacy of the standard contextualist claim about our intuitive judgments is a subject of lively and ongoing debate; see Chapter 3 for a more detailed and sympathetic discussion of this line of criticism.

\section{Why The Intuitions Should Be Trusted}

Deferring to the intuitive judgments gives us strong reason to accept Truth. But why defer to the intuitions to begin with? Why think that the seeming truth and propriety of his claims indicates that they are proper and true? This question points towards the vast controversy over the role of intuitions in philosophy; see Pust 2016 for an introduction to this literature.

It is a widely accepted philosophical practice to afford the contents of our intuitive judgments a default level of evidential significance. The practice is not to treat intuitive judgments as infallible or issuing from some faculty of rational intuition, but simply to treat acceptance of their contents as a

\footnotetext{
${ }^{2}$ Consistent with his earlier study, Buckwalter's respondents also judged that speakers who claim not to know in Low cases and speakers who claim to know in High cases were speaking truly. This wrinkle leads Buckwalter to suggest that all of the responses were "largely driven by accommodation;" i.e., the conversational rule-schema David Lewis posited to the effect that speakers ought, so far as possible, to assign semantic values to utterances that permit them to be interpreted as true (Lewis 1979). Contextualist should welcome Buckwalter's suggestion. If the reason that subjects so readily interpret "know"-involving utterances as true is that they are tacitly adhering to a rule of accommodation for such utterances, then we have a further piece of "intuitive" evidence for contextualism: the more semantically invariant a term, the more resistant we should be to accommodating a variety of "surfacecontradictory" utterances involving the term.
} 
desideratum when tallying the pros and cons of a philosophical view. When the balance of reasons tips in favor of a view, despite its conflict with some intuitive judgments, standard practice tells us to "bite the bullet" and dismiss the problematic intuitions. Yet even when biting the bullet, we are encouraged to provide an explanation for the wayward intuitions. Fairly powerful reasons are required to conclude that things are not how they intuitively seem, and we may remain dissatisfied with a bullet-biting view until we have been told why things intuitively but wrongly seemed as they did. Employing this standard practice in the present context, the intuitions that Keith's utterances are both proper and true ought to be taken at face value. And to take them at face value is to endorse Truth. If we are to reject them, we are owed an explanation as to why we had them to begin with.

Of course, to describe this practice is not to justify it. Controversy surrounds all general defenses of reliance on intuition in philosophy. A more manageable strategy here may be to pursue a narrower defense. Jennifer Nagel argues that "epistemic evaluations of particular cases" of the sort frequently discussed by epistemologists (e.g., intuitive judgments about Gettier's cases, Carl Ginet's fake barn country, Lawrence Bonjour's Truetemp case) are exercises of our capacity to attribute mental states to other people (Nage12007, 2012). Though our "mindreading" ability is susceptible to error, it is nonetheless generally accurate. If Nagel is right about the source of our intuitive epistemic evaluations, then we can be confident in treating them as evidentially significant (if defeasible). But Nagel's defense of epistemic intuitions, even if successful, may not establish the significance of the contextualist intuitions about Low-High pairs, because the latter may not count as epistemic intuitions; they concern the truth and propriety of knowledge claims, and not whether the subjects of those claims know.

Since the intuitions concern claims made by uttering sentences, we may wish to treat them as linguistic intuitions. Linguists treat the intuitive judgments of competent speakers about certain features of their language as an important source of evidence about those features of the language. The standard rationale for treating such intuitions as evidence is that linguistic competence relies on tacit knowledge of the rules governing the language (Chomsky 1986). On the assumption that a linguistic intuition is the product of a speaker's tacit knowledge of the rules governing their language, we have good reason to 
accept it. While there is substantial controversy over the adequacy of this traditional rationale (see, e.g., Devitt 2006), it seems undeniable that competent speakers of a language possess at least some degree of epistemic authority concerning many features of their language. If the intuitive judgments of truth and propriety in Low-High pairs are linguistic intuitions, then they have a prima facie claim to deference, on pain of undermining a principle source of evidence in linguistics.

However, just as it is not clear that the intuitions are epistemic, it's also not clear that they are best characterized as properly linguistic, either. They don't concern the properties of words or sentences, but the claims made by uttering sentences in particular contexts. The competence required to determine what claim is being made by a speaker who utters a particular sentence involves a substantial degree of extralinguistic knowledge, as does that required to form an accurate judgment about whether a claim is true or conversationally proper. Suppose that Mary utters, "Sharon is by the bank." Linguistic competence alone won't enable you to know whether she is claiming that Sharon is waiting by a financial institution, or that Sharon is down by the riverbank, much less whether Mary's claim is proper or true. Similarly, tacit knowledge of the syntactic and semantic features of the linguistic expressions he uses doesn't suffice for us to know what Keith claims by uttering, "Well, no, I don't know," much less to form a judgment as to whether his claim is true or proper. Intuitions of truth and propriety rest in part upon empirical knowledge of how speakers in various circumstances use particular English sentences, together with our capacity to imaginatively occupy the circumstances described in the case.

But even if the intuitions do not rest entirely upon tacit linguistic knowledge, their being the product of our competence as users of English gives us good reason to treat them with respect. Fluent speakers possess practical expertise concerning how to use their language. They are in a position to know what sentences speakers tend to utter in various situations, what speakers typically mean to claim by uttering what they do, and which claims are appropriate to make under which circumstances. The intuitive judgments of competent speakers about the truth and propriety of claims made using their language thus deserve deference for the same reason that the judgments of anyone with practical expertise in any particular area do: expertise in a practice gives you reliable (though not infallible) intuitions about how 
the practice works. When a chef who has been making mayonnaise for years tells you that you're adding the oil to your emulsion too quickly, you ought to listen. A seasoned jazz musician can tell you, without appeal to theory, whether a given note will sound awkward at a particular moment in an improvised sequence. Similarly, given sufficient background information, a fluent speaker of English can tell you whether a claim made using English in a particular circumstance would be proper, and whether it would be true. ${ }^{3}$

\section{Contextualism and Its Invariantist Rivals}

The rest of the intuitive argument for contextualism is devoted to showing that contextualism is better able than its rivals to accommodate and explain Truth. Keith's claims are "surface-contradictory". Making what is implicit in the uttered sentences explicit, the two claims are:

(L) I know [that the bank will] be open.

(H) I don't know [that the bank will be open].

Going by their surface grammar, $(\mathrm{L})$ and $(\mathrm{H})$ are contradictories. So how could both claims be true? We assume that the bank will be open, and that Keith believes this in both cases. Keith has no evidence against the bank's being open in High that he lacks in Low. His epistemic position with respect to the

\footnotetext{
${ }^{3}$ DeRose suggests that correct semantic theory of a term is correct partly in virtue of the fact that we have the semantic intuitions about the term that we do, together with other facts about our usage of the term (DeRose 2009, 66-67). He concludes that ordinary usage facts indicating that a term is context-sensitive are thus "some of the best possible type of evidence you could ask for" to conclude that the term is, in fact, context-sensitive. Against this, Cappelen and Lepore argue that intuitions of the sort we have been discussing --- intuitions about truth and propriety generated by what they call "minimal pairs" --- provide no evidence that a term is semantically context-sensitive (Cappelen and Lepore 2005, 17). Their target is specifically the view that the word "know" should be categorized as an indexical term. (Indeed, as speech-act pluralists, they agree with contextualists that the same sentence can be used to make claims with different truth-conditions in different contexts.) Though the claim that "know" is an indexical term has sometimes been thought to be constitutive of contextualism, contextualists are free reject inde xicalism about "know". See Stainton 2010, Pynn 2016, and chapter 37 for further discussion of these issues.
} 
proposition that the bank will be open is the same in both cases. How, then, can he truly claim (L) in Low, but truly claim $(\mathrm{H})$ in High? Contextualism provides a simple answer: whether Keith can truly claim to know something varies with the epistemic standard in the context in which he makes the claim. Since the standard in Low is relatively low, while the standard in High is relatively high, his epistemic position is strong enough for him to count as knowing in Low, but not for him to count as knowing in High.

Invariantists hold that the epistemic standards governing the truth of a knowledge claim are fixed across contexts, and so cannot agree that $(\mathrm{L})$ and $(\mathrm{H})$ are both true owing to a variation in the epistemic standards across the contexts of utterance. Traditionally, invariantists have attempted to block the intuitive inference to Truth by providing alternative explanations for the intuitions that support it. In more recent years, clever versions of invariantism have been developed that accept Truth, and propose ways to explain it, rather than biting the bullet.

Traditional invariantists hold that one of Keith's claims is false. Skeptical invariantists hold that the standard is very demanding, and hence that Keith's claim to know in Low is false. Moderate invariantists hold that the standard is more relaxed, and hence that Keith's claim not to know in High is false. In either case, one intuition of truth must go. Invariantists have nonetheless been keen to accommodate both intuitions of propriety. This leads to two challenges. The first is to explain how the false claim is nonetheless proper. Let's call this the propriety challenge. The second is to explain the wayward intuition of truth. Let's call this the truth challenge.

A common strategy for meeting the propriety challenge focuses on the pragmatic effects of knowledge claims (see Chapter 19). False claims can pragmatically convey truths, and in virtue of this may be conversationally proper, despite being false. Jessica Brown 2006 offers a pragmatic answer to the propriety challenge on behalf of moderate invariantism. If Keith were to claim that he knows in the High case, his assertion would, though true, be irrelevant, because the conversationally relevant issue is not whether he knows, but whether he is in an especially strong epistemic position. So he falsely claims that he doesn't know, conveying the conversationally relevant truth that he is not in an especially strong epistemic position (for other proposals in this vein see Rysiew 2001 and 2007, Black 2005, Hazlett 2007, 
and Pritchard 2010). Skeptical invariantists have made parallel proposals. Jonathan Schaffer 2004 treats ordinary knowledge claims as hyperbole, arguing that such hyperbolic falsehoods convey that the speaker can eliminate the possibilities of error relevant in the context of utterance. Wayne Davis 2007 offers a different kind of pragmatic skeptical account of the propriety of Low knowledge claims, arguing that they are examples of "loose use," proper for the same reason that it can be proper to claim, falsely, that a jar with only a few coffee grounds left is empty (see chapter 17).

Though promising as an answer to the propriety challenge, the pragmatic approach faces a significant hurdle in meeting the truth challenge. There are no uncontroversial examples of false claims that seem true in virtue of being proper. The central cases of false-but-proper claims --- examples involving figurative speech --- do not produce an intuition of truth. And though Davis is surely right that it is often proper to call a coffee jar with a couple of beans in it empty, some (the present author included) hold that this is in part because such claims are often true: the standards for emptiness fluctuate with context. If this is correct, Davis's proposal treating ordinary knowledge claims as instances of loose use may amount to a version of contextualism, rather than a competitor. It is common for invariantists who recognize the limitations of the pragmatic approach to the truth challenge to attempt to meet it with an error theory of some kind. Timothy Williamson, for example, suggests that repeated exposure to unusual skeptical possibilities can produce an "illusion of epistemic danger" (Williamson 2005; see also Vogel 1990). High context speakers, under the sway of such an illusion, may be led to underestimate the strength of their epistemic positions. More recently, Mikkel Gerken 2013 has developed a theory of what he calls "epistemic focal bias," which may produce inaccurate impressions of knowledge and nonknowledge. There is some tension between the error-theoretic approach to the truth challenge and pragmatic resolutions of the propriety challenge. A claim that results from an error may seem proper, but once the error is uncovered, we generally change our minds about its propriety. It is not clear that invariantists can endorse the intuition of propriety while rejecting the intuition of truth (though see Pynn 2014 for an attempt to do both). 
Other invariantists accept Truth. One prominent strategy is to offer a psychological explanation for the falsehood of Keith's claim in High. Kent Bach argues that in a High context a speaker's 'threshold for (confidently) believing" goes up, so that she "demands more evidence than knowledge requires" before she is willing to form a confident belief (Bach 2005, 77). Jennifer Nagel (2008, 2010a, 2010b) relies on an array of psychological studies to argue that subjects in high stakes situations require more information before forming settled beliefs, and so tend to refrain from forming settled beliefs on the basis of information that low stakes subjects treat as sufficient for settled belief. Since high stakes decrease a subject's "need for closure," Keith will be less inclined to form a settled belief about the bank's hours in High than he was in Low. The Bach-Nagel strategy is then to say that Keith doesn't have a settled belief that the bank will be open in High. Since knowledge requires belief, Keith doesn't know in High, and his claim in High is true (see chapter 7).

Another invariantist strategy for accommodating Truth is to argue that the epistemic position required for knowing varies with the subject's practical situation. Proponents of interest-relative or sensitive invariantism say that whether a subject's epistemic position is strong enough to know that $\mathrm{P}$ depends upon the practical significance for her of the question of whether $\mathrm{P}$ is true (see chapter 20). On this picture, when the costs of being wrong about $\mathrm{P}$ are high, you need to be in a stronger epistemic position to know that $\mathrm{P}$ than you do when the costs of being wrong are low. Sensitive invariantism predicts that $(\mathrm{L})$ and $(\mathrm{H})$ are both true: since the practical stakes are higher for Keith in High than they are in Low, a stronger epistemic position is required for him to know in High than in Low. This approach rests on a claim known as anti-intellectualism or impurism; namely, that the epistemic requirements for knowing vary with the subject's practical situation. Anti-intellectualism is controversial, though it has able defenders, and its capacity to enable invariantists to accommodate our intuitions about Low-High pairs is a significant consideration in its favor (see Stanley 2005 and Fantl and McGrath 2009 for major defenses of interest-relative invariantism and impurism, respectively; see also Hawthorne 2004).

Taking one of these approaches enables invariantists to avoid the propriety and truth challenges. But the challenges re-emerge when we make a slight alteration to the structure of a Low-High pair. The 
bank cases involve first-person knowledge ascriptions made in different scenarios. This makes room for positing some variation in Keith's psychological state or practical situation between the Low and High scenarios, which explains how $(\mathrm{L})$ and $(\mathrm{H})$ can both be true, even though contextualism is false. But we can also construct Low-High pairs where the surface-contradictory claims concern a third party. Such "third-person" cases elicit the same intuitive judgments as the original Bank Cases, but there is no room to posit a difference in the third-party subject's mental states or situation to account for the truth of two surface-contradictory claims. DeRose's Thelma and Louise Cases are designed for just this purpose (DeRose 2009, 4-5; Cohen 1999's airport cases also have this structure). Thelma, Louise, and Lena are co-workers. All three saw their colleague John's hat in the hallway and overheard a conversation whose participants presupposed that he was in his office. All three believe that John was in, though they did not actually see him:

Low Thelma. On her way home, Thelma stops at the local tavern to collect on a small bet concerning whether John would be in that day. After her tavern-mates pay up, they ask her whether Lena knows that John was in, since she also had a small bet going on the question. "Yes," Thelma answers, "Lena knows that John was in."

High Louise. Louise is stopped by the police on her way home. They are investigating a serious crime, and need to verify whether John was at work today. They have no reason to doubt that he was, but need Louise's testimony to be sure. She demurs, pointing out that he may have left his hat on the hook the previous day, and that her co-workers who thought he was in may have been mistaken. After all, she points out, she didn't actually see him. So while she believes he was in, she says, she doesn't know. They follow up by asking whether Lena could testify to John's whereabouts. No, Louise answers, she didn't see him either: 'Lena doesn't know that John was in." 
Thelma and Louise's claims about Lena both seem proper and true when considered against the backdrop of their contexts of utterance. These intuitions, in turn, underwrite:

Truth*. Thelma's claim that Lena knows in Low and Louise's claim that Lena doesn't know in High are both true.

Contextualism accommodates and explains Truth* in precisely the same way it did Truth. But assuming that Thelma and Louise are speaking simultaneously, Lena's confidence level and practical circumstances must be the same in each case. So we cannot posit a psychological or practical difference to accommodate and explain Truth*. Bach and Nagel both appeal to error theories to handle such third-person cases, chalking the intuitive truth of claims like Lena's up to a kind of error (Bach 2005, 76-77; Nagel2010b). Stanley takes a somewhat different tack, suggesting that in considering whether Lena knows, Louise is actually concerned with whether Lena would know if she were in Louise's situation. Since she wouldn't, Louise claims that Lena doesn't know; according to Stanley this is "a perfectly intuitive explanation of the intuitions" (Stanley 2005, 102). That may be, though to the extent that an explanation's simplicity and unity counts in its favor, contextualism is preferable to either of these approaches.

\section{Cross-Contextual Intuitions: Trouble for Contextualism?}

Insofar as a view's capacity to explain how the contents of our intuitive judgments are true contributes to its superiority over rivals, contextualism so far appears superior to invariantism. However, opponents of contextualism have argued that some of our intuitions are at odds with contextualism. These problematic intuitions primarily concern various forms of disagreement, and cross-contextual assessments (see chapter 20). For example, imagine the conversation in High Louise continuing: 
High Louise, Con't. The police point out that Thelma was overheard in the tavern claiming that Lena knows that John was in, and ask her what she thinks of that. "No, Thelma's claim was false," Louise replies. "Lena doesn't know" (cf. McKenna 2014, 726).

According to contextualism, Thelma's claim was true. Assuming that Louise's assessment of Thelma's claim is intuitively correct, we appear to have an intuition whose content contextualists must reject. A number of theorists have argued that such assessments furnish intuitive evidence against contextualism (e.g. Williamson 2005, 220, Stanley 2005, 52, MacFarlane 2005, 202-203, Brogaard 2008, 411).

Note that if this case provides evidence against contextualism, it also provides evidence against moderate and sensitive invariantism, at least on the assumption that those views treat Thelma's claim in Low as true. Skeptical invariantists may regard the datum as a point in favor of their own view. However, skeptical invariantists already reject many ordinary intuitions of truth; on their view, ordinary positive knowledge claims are almost always false, despite our persistent everyday intuitions to the contrary. So even granting that the case is an intuitive cost for contextualism as compared to skeptical invariantism, it hardly tips the intuitive balance in skeptical invariantism's favor.

We may question the degree to which such cases are intuitively problematic for contextualism. Prominent Low-High pairs are designed to capture what ordinary speakers would say in relevantly similar circumstances. By contrast, it is not clear that an ordinary speaker in circumstances like Louise's would say, "Thelma's claim was false." Provided she were aware of the casual nature of Thelma's tavern conversation, it would be at least as natural for her to say, "Thelma was only speaking loosely," or even, "She didn't really mean that Lena knows for sure." Neither of these assessments would conflict with contextualism; indeed, either of them would provide some indirect confirmation that different standards are operative in each context. Of course, Louise could say that Thelma's claim was false, and to the extent that such an assessment would be intuitively correct, this is a fair point against contextualism. But if it is 
not what Thelma most naturally would say, the point is not especially threatening, especially given the intuitive costs already borne by invariantism. ${ }^{4}$

Such cross-contextual assessments play an important role in motivating a newer competitor to contextualism, known as relativism about knowledge attributions (see chapters 25 and 26). According to the relativist, the truth-conditions of a knowledge claim vary not with the context of utterance, but the context of assessment (see MacFarlane 2005, MacFarlane 2014 (ch. 8), and Rysiew 2011). Relativists can treat Thelma's claim as true relative to her own context of assessment, but false relative to Lena's. So relativism can accommodate both the intuitive truth of Thelma's knowledge attribution, and the intuitive truth of Lena's assessment of Thelma's knowledge attribution as false. There may be intuitive costs associated with relativism as well, however. According to the relativist, Thelma's claim was true as assessed in Thelma's context of utterance, but it seems doubtful that Lena would be prepared to grant this. Montminy 2009 argues that the relativist must impute to ordinary speakers a kind of semantic error in their cross-contextual judgments. But relativism is an important emerging paradigm in philosophical semantics, and the question of whether contextualism or relativism better accommodates and explains our intuitions about knowledge claims remains open.

\section{Bibliography}

Bach, K. (2005). “The Emperor's New 'Knows'.” In Preyer, G. and Peter, G., editors, Contextualism in Philosophy: Knowledge, Meaning, and Truth, pages 51-90. Oxford University Press.

Black, T. (2005). “Classical Invariantism, Relevance and Warranted Assertibility Manoeuvres.” The

\footnotetext{
${ }^{4}$ See also DeRose's considerations in favor of the "methodology of the straightforward," on which the "simple positive and negative claims speakers make utilizing the piece of language being studied" receive greater weight than "more complex matters, like what metalinguistic claims speakers will make and how they tend to judge how the content of one claim compares with another" (DeRose 2009, 153).
} 
Philosophical Quarterly, 55(19):328-336.

Brogaard, B. (2008). "In Defense of a Perspectival Semantics for 'Know'.” Australasian Journal of Philosophy, 86(3):439-459.

Brown, J. (2006). “Contextualism and Warranted Assertibility Manoeuvres.” Philosophical Studies, 130:407-435.

Buckwalter, W. (2010). “Knowledge isn't Closed on Saturday: A Study in Ordinary Language.” Review of Philosophy and Psychology, 1(3):395-406.

Buckwalter, W. (2014). “The Mystery of Stakes and Error in Ascriber Intuitions.” In Beebe, J., editor, Advances in Experimental Epistemology. Continuum.

Cappelen, H. and Lepore, E. (2005). Insensitive Semantics: A Defense of Semantic Minimalism and Speech Act Pluralism. Blackwell Publishing.

Chomsky, N. (1986). Knowledge of Language: Its Nature, Origin, and Use. New York: Praeger

Publishers.

Cohen, S. (1999). "Contextualism, Skepticism, and the Structure of Reasons." Philosophical Perspectives, 13:57-89.

Davis, W. (2007). “Knowledge Claims and Context: Loose Use.” Philosophical Studies, 132:395-438.

DeRose, K. (1992). “Contextualism and Knowledge Attributions.” Philosophy and Phenomenological Research, 52:913-929.

DeRose, K. (2005). “The Ordinary Language Basis for Contextualism, and the New Invariantism.” The Philosophical Quarterly, 55:172-198. 
DeRose, K. (2009). The Case for Contextualism. Oxford University Press, Oxford.

DeRose, K. (2011). “Contextualism, Contrastivism, and X-Phi Surveys.” Philosophical Studies, 156:81110.

Devitt, M. (2006). “Intuitions in Linguistics.” British Journal for the Philosophy of Science, 57(3):481513.

Fantl, J. and McGrath, M. (2009). Knowledge in an Uncertain World. Oxford University Press.

Feltz, A. and Zarpentine, C. “Do You Know More When It Matters Less?” Philosophical Psychology, 23:683-706.

Gerken, M. (2013). “Epistemic Focal Bias.” Australasian Journal of Philosophy, 91(1):41-61.

Hansen, N. and Chemla, E. (2013). "Experimenting on Contextualism.” Mind and Language, 28(3):286321.

Hawthorne, J. (2004). Knowledge and Lotteries. Oxford University Press.

Hazlett, A. (2007). “Grice’s Razor.” Metaphilosophy, 38(5):669-690.

Hume, D. (1999). An Enquiry Concerning Human Understanding. T. D. Beauchamp, ed. Oxford: Oxford University Press.

Lewis, D. (1979). “Scorekeeping in a Language Game.” Journal of Philosophical Logic, 8:339-359.

MacFarlane, J. (2005). "The Assessment Sensitivity of Knowledge Attributions." Oxford Studies in Epistemology, 1:197-234.

MacFarlane, J. (2014). Assessment Sensitivity: Relative Truth and Its Applications. Oxford: Oxford University Press. 
McKenna, R. (2014). “Shifting Targets and Disagreements.” Australasian Journal of Philosophy, 92(4): $725-742$.

Montminy, M. (2009). “Contextualism, Relativism and Ordinary Speakers' Judgments.” Philosophical Studies, 143(3):341-356.

Nado, J. and Johnson, M. (2014). “Moderate Intuitionism: A Metasemantic Account.” In A.R. Booth and D. Rowbottom, eds., Intuitions. Oxford: Oxford University Press.

Nagel, J. (2007). “Epistemic Intuitions.” Philosophy Compass, 2: 792-819.

Nagel, J. (2008). "Knowledge Ascriptions and the Psychological Consequences of Changing Stakes." Australasian Journal of Philosophy, 86(2):279-294.

Nagel, J. (2010a). "Knowledge Ascriptions and the Psychological Consequences of Thinking About Error.” The Philosophical Quarterly, 60(239):286-306.

Nagel, J. (2010b). "Epistemic Anxiety and Adaptive Invariantism.” Philosophical Perspectives, 24:407435

Pritchard, D. (2010). “Contextualism, Skepticism, and Warranted Assertability Manoeuvres.” In Campbell, J. C., O’Rourke, M., and Silverstein, H., editors, Knowledge and Skepticism, pages 85-103. MIT Press.

Pust, J. (2016). "Intuition.” The Stanford Encyclopedia of Philosophy (Spring 2016 Edition). E. N. Zalta, ed. URL $=\langle$ http://plato.stanford.edu/archives/spr2016/entries/intuition/〉.

Pynn, G. (2014). “Unassertability and the Illusion of Ignorance.” Episteme, 11(2): 125-143.

Pynn, G. (2015). “Pragmatic Contextualism.” Metaphilosophy, 46(1):26-51. 
Rysiew, P. (2001). "The Context-Sensitivity of Knowledge Attributions.” Noûs, 35:477-514.

Rysiew, P. (2007). “Speaking of Knowing.” Noûs, 41(4):627-662.

Rysiew, P. (2011). "Relativism and Contextualism." In Hales, S. D., editor, A Companion to Relativism, 286-305. Blackwell.

Schaffer, J. (2004). "Skepticism, Contextualism, and Discrimination." Philosophyand Phenomenological Research, 69(1):138-155.

Schaffer, J. and Knobe, J. (2012). “Contrastive Knowledge Surveyed.” Noûs, 46(4):675-708.

Stainton, R. J. (2010). “Contextualism in Epistemology and the Context Sensitivity of 'Knows'.” In O’Rourke, M. and Silverstein, H., editors, Knowledge and Skepticism, pages 113-139. Cambridge, MA: MIT Press.

Stanley, J. (2005). Knowledge and Practical Interests. Oxford University Press.

Vogel, J. (1990). “Are There Counterexamples to the Closure Principle?” In Roth, M. and Ross, G., editors, Doubting: Contemporary Perspectives on Skepticism, pages 13-27. Kluwer, Dordrecht.

Williamson, T. (2005). "Contextualism, Subject-Sensitive Invariantism and Knowledge of Knowledge." The Philosophical Quarterly, 55(219):213-23 